\title{
Mapeamento do fluxo de valor de uma família de produtos descartáveis em uma empresa de produtos médico-hospitares
}

\author{
Value stream mapping of a disposable products family in a company of the \\ medical and hospital products
}

\author{
Ariane Ferreira Porto Rosa ${ }^{1 *}$, Eduardo Angelin ${ }^{1}$, Rogério Royer ${ }^{1}$
}

\begin{abstract}
RESUMO
O presente trabalho tem como objetivo propor melhorias no processo produtivo por intermédio do Mapeamento do Fluxo de Valor e da utilização das ferramentas da produção enxuta e da qualidade em um estudo de caso em uma empresa do setor da saúde. A metodologia utilizada classifica-se como exploratória, aplicada, quali-quantitativa com a realização de um estudo de caso. Dessa forma, foi realizado um estudo de caso em uma indústria do setor da saúde, sendo aplicado inicialmente um mapeamento de processos e, posteriormente, a elaboração do mapeamento do fluxo de valor atual e futuro. A transição do estado atual para o estado futuro ocorreu por meio da aplicação de planos de ações, construídos de maneira organizada, com a finalidade de reduzir estoques intermediários, alterar o sistema de produção e, consequentemente, otimizar os fluxos de materiais e informações. Nesse estudo, foi possível reduzir o lead time de produção e tempo de ciclo em aproximadamente um terço dos tempos atuais, melhorar os processos e reduzir desperdícios que não agregar valor ao produto.
\end{abstract}

Palavras-chave: Mapeamento do Fluxo de Valor; Sistema da Qualidade; Produção Enxuta; Indústria setor saúde.

\section{ABSTRACT}

This paper aims to propose improvements in the production process through the Value Stream Mapping and the use of tools of lean production and quality in a case study on a company manufacturer of health sector. The methodology used is classified as exploratory, qualitativequantitative, with the accomplishment of a case study. Thus, a case study was carried out in a healthcare industry, initially mapping processes and, later, the current and future Value Stream Mapping. The transition from the current state to the future state will occur through the application of action plans, organized in order to reduce intermediate stocks, change the production system and, consequently, optimize the flows of materials and information. In this study, it was possible to reduce production lead time and cycle time by approximately one-third of current times, improve processes and reduce waste that does not add value to the product.

Keywords: Value Stream Mapping; Quality System; Lean Manufacturing; health sector industry.

${ }^{1}$ UFPel - Universidade Federal de Pelotas. *E-mail: afprosa61 @ gmail.com 


\section{INTRODUÇÃO}

As indústrias vêm buscando gradativamente a melhoria em suas atividades e operações de forma a manterem-se competitivas no mercado. O crescimento da demanda produtiva e clientes cada vez mais preocupados com a qualidade e a procedência do que consomem, têm exigido que as indústrias inovem não apenas seus produtos, mas seus sistemas produtivos.

O bom desempenho dos processos está diretamente ligado a sobrevivência do empreendimento. Percebe-se ainda, que o caminho para o melhor custo benefício não está em elevar o preço do produto, e sim em encontrar soluções que reduzam seu custo. Para conseguir uma maior agregação de valor no processo produtivo e, consequentemente, ganhos em competitividade, é preciso um planejamento de produção eficiente e alinhado.

Um sistema produtivo pode ser entendido como um conjunto de processos que proporcionam a obtenção de um dado produto final. Estes processos têm como objetivo produzir um determinado produto ou serviço, que agregue valor para os clientes e, consequentemente, para a empresa em si, tanto em nível macro quanto micro ambiental.

Gaither e Frazier (2001) e Martins e Laugeni (2005), ressaltam a importância de se entender a produção como um sistema inteiro e interdependente, o qual envolve entrada de insumos, transformação, saída de produtos e controle de resultados para manter a melhoria contínua do processo.

Neste contexto, a mentalidade enxuta de produção (Lean Manufacturing - LM) tornou-se a principal aliada para otimizar os processos produtivos. Através do mapeamento de processos (MP), do mapeamento do fluxo de valor (MFV) e de ferramentas Lean para implementação de melhorias, torna-se possível identificar e eliminar perdas em processos para determinada família de produtos.

Enquanto o mapeamento de processos ajuda a identificar as fontes de desperdício em uma linguagem de mais fácil acesso, o mapeamento do fluxo de valor se propõe a compreender as relações entre o fluxo da produção e da informação. Aliando as duas práticas, obtém-se um modelo eficiente de gerenciamento, capaz de criar subsídios para tomada de decisões e criação de planos de ação para uma melhoria na cadeia produtiva.

A utilização da ferramenta MFV se justifica porque ela é uma ferramenta estratégica que possibilita uma visão sistêmica, demonstrando as oportunidades de 
melhorias e permitindo a utilização de outras ferramentas da Produção Enxuta. Além disso, muitas empresas focalizam mais esforços na qualidade vinculada diretamente ao produto, deixando de analisar o sistema produtivo em sua totalidade e postergando a atuação nos gargalos e desperdícios da produção.

O principal objetivo desse trabalho é apresentar as melhorias propostas em um processo produtivo utilizando MP, MFV, ferramentas da produção enxuta e da qualidade em um estudo de caso em uma empresa fabricante de equipamentos e artigos médicos e hospitalares situada na cidade de Pelotas no RS.

Assim, a problemática de pesquisa deste trabalho é: Como identificar e eliminar as perdas do processo de produção de uma família de descartáveis, de forma que acarrete na diminuição de custos, garantindo a funcionalidade e aplicabilidade do produto?

Embora o método de pesquisa proposto neste trabalho possa ser aplicado em outras famílias de produtos similares da empresa, o estudo de caso realizado é único com foco em uma família de produtos e, portanto, os resultados obtidos delimitam-se ao escopo deste trabalho específico e que fortalece o método e suas ferramentas quando aplicado a indústria no geral, de modo a validar ganhos quando seguidos suas etapas precisamente.

Este artigo encontra-se estruturado em cinco seções. A primeira seção mostra esta introdução contendo um panorama geral do trabalho realizado. A segunda seção apresenta a revisão teórica necessária para a realização do estudo. Na seção 3 descreve-se a metodologia utilizada. A seção 4 apresenta o estudo de caso realizado. Na seção 5 são apresentadas as conclusões deste trabalho. Por fim, são apresentadas as bibliografias referenciadas.

\section{REFERENCIAL TEÓRICO}

A revisão teórica busca apresentar conceitos sobre Mapeamento de Processos, Produção Enxuta, Mapeamento do Fluxo de Valor (MFV) e de forma sucinta algumas Ferramentas da Qualidade. Os pontos levantados buscam passar maior entendimento sobre o assunto e detalhar todas as escolhas feitas durante a realização deste trabalho. Para isso, são apresentados métodos e ferramentas de engenharia de produção, adequados para auxiliar nas decisões e realização deste estudo.

\subsection{Mapeamento de processos}


Segundo Cheung e Bal (1998), o mapeamento de processos pode ser definido como uma técnica de orientação para desenvolvimento, projeto ou avaliação dos processos existentes em um determinado setor, departamento ou, até mesmo, uma organização inteira.

Existem diversas técnicas de mapeamento que nos apresentam diferentes enfoques, de acordo com a necessidade do processo, podem ser abordadas separadamente ou em conjunto. Para facilitar a aplicação do mapeamento de processos, Tseng et al. (1999) sugere que a apresentação seja feita utilizando uma linguagem gráfica, descrevendo de forma precisa e detalhada as interfaces do processo mapeado, desempenhando assim uma análise consistente e adequada ao vocabulário do projeto.

A ferramenta de mapeamento mais utilizada, é o fluxograma. De acordo com Barnes (1982), o fluxograma de processo é uma técnica utilizada para registrar o processo de uma maneira compacta e de fácil visualização e entendimento.

Um fluxograma traça o fluxo de informação, pessoas, equipamentos, ou materiais através das várias partes do processo. Fluxogramas são traçados com caixas contendo uma breve descrição do processo e com linhas e setas que mostram a sequência de atividades. O retângulo é a usual escolha para uma caixa do fluxograma, porém outras formas geométricas podem diferenciar tipos de atividades (PINTO, 2007).

Segundo Slack (1997), o fluxograma é uma técnica de mapeamento que permite o registro de ações de algum tipo e pontos de tomada de decisão que ocorrem no fluxo real. A principal vantagem da utilização de um fluxograma é verificar como se relacionam as etapas de um processo, o que permite uma melhor análise de seu fluxo. Ele pode também facilitar a localização das deficiências do sistema, pois propicia claro entendimento devido a sua interface gráfica.

\subsection{Produção Enxuta}

A Produção Enxuta parte da pressuposição da existência de sete tipos de desperdícios em uma empresa, sendo uma finalidade sua tentar eliminar custos que não geram valor para a empresa (OHNO, 1997). 
As perdas na superprodução devem ser evitadas à medida que elas escondem as outras perdas. Exemplos desse tipo de perda são: necessidade de retrabalhar o produto, refugos, quebra de máquinas e ineficaz previsão de demandas (CORRÊA et al., 1996).

Os deslocamentos desnecessários de insumos e produtos que geram custos e não agregam valor consistem nas perdas por transporte. Já as perdas no processamento são as atividades de processamento ou fabricação que são desnecessárias para o produto, gerando custos e não agregando valor ao produto entregue ao cliente/consumidor.

As perdas nos produtos não conformes ocorrem quando são fabricados produtos, peças ou componentes que não obedecem às especificações técnicas e da qualidade. Perdas nos estoques são produtos acabados, materiais em processo e matérias-primas em excesso que geram elevados custos financeiros e utilizam o espaço físico que poderia ser atribuído à outras operações. Para evitar isso, é impreterível buscar o nivelamento da capacidade da empresa com sua demanda, sincronizar a produção e produzir em pequenos lotes.

Quando ocorre ociosidade da mão-de-obra, ou seja, tempo o qual o trabalhador fica sem trabalhar devido a uma quebra de máquina, tempo de setup, entre outros consiste nas perdas por espera. Para reduzir essas perdas, recomenda-se aplicar ferramentas como a Manutenção Produtiva Total (Total Productive Maintenance, TPM).

As perdas no movimento são quaisquer movimentos desnecessários dos trabalhadores quando forem operar uma máquina ou quando estiverem na linha de montagem. Algumas ferramentas foram criadas para melhorar a eficiência dos trabalhadores: o estudo dos tempos e o estudo do movimento, uma vez que movimento está diretamente relacionado com o tempo.

A Produção Enxuta, além do esforço para eliminação dos desperdícios, caracteriza-se também pela não aceitação da situação vigente ou ainda de padrões arbitrários de desempenho (CORRÊA et al., 1996). As metas propostas na produção enxuta para solução dos vários problemas de produção são: zero defeitos; tempo zero de preparação (set up); estoque zero; movimentação zero; quebra zero; lead time zero; e lote unitário (SHINGO, 1996).

O modelo de Produção Enxuta possui várias metodologias e técnicas de produção e gestão industrial que são utilizadas atualmente pelas empresas. Algumas dessas surgiram no decorrer das últimas décadas, como por exemplo: Just-In-Time (JIT); Total Quality Management (TQM); Total Productive Maintenance (TPM); e Filosofia Kaizen. 
Para Rother e Shook (2012), o MFV surgiu para preencher os objetivos supracitados, enfocando todo o fluxo de produção de um produto ou família de produtos, visando à implantação da Produção Enxuta em todo o fluxo.

\subsection{Mapeamento de Fluxo de Valor}

O MFV é uma ferramenta de planejamento e comunicação utilizada na produção enxuta. Essa ferramenta serve para visualizar todos os fluxos de informações e de materiais para a fabricação de um produto, desde os fornecedores de matéria-prima até os clientes finais (ROTHER e SHOOK, 2012).

Conforme Silveira (2017), o MFV é baseado na construção de um mapa que mostra como é o fluxo de materiais ou informações. O mapa começa na cadeia de fornecedores, passa pela empresa e termina no cliente, ou seja, ele atravessa todo o caminho do processo de criação do produto. A figura 1 apresenta as etapas gerais para aplicação do MFV.

Figura 1 - Etapas gerais do MFV

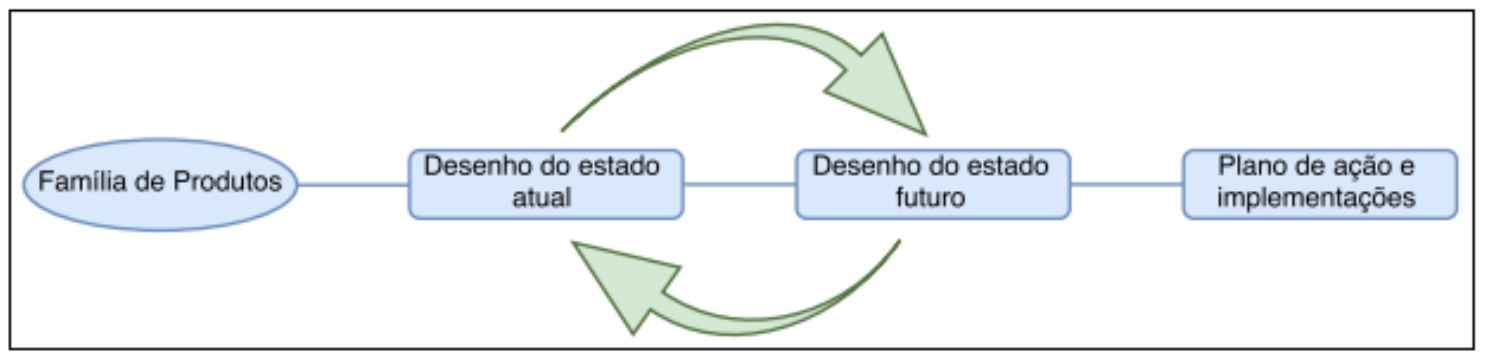

Fonte: Adaptado Rother e Shook (2012)

Para iniciar a construção do MFV não é necessário mapear tudo o que está presente no chão de fábrica, uma vez que os clientes finais e consumidores estão preocupados apenas com determinados produtos e não com toda a gama que há na empresa (ROTHER e SHOOK, 2012).

A partir disso, para a aplicação da ferramenta MFV, inicialmente é necessário focalizar uma família de produtos, que é um conjunto de produtos que passam por processos similares e possuem configurações parecidas, que pode ser feita levando em conta algumas variáveis, tais como: produtos mais vendidos, processos ineficientes e produtos que exijam menor tempo de entrega.

Após a seleção da família de produtos a ser mapeada, é fundamental criar um mapa que demonstre como ocorrem os fluxos de materiais e de informações atualmente na linha de produção. A coleta de dados deve ser feita por alguém que caminhe juntamente 
com os respectivos fluxos, realizando um processo "de trás para frente", ou seja, começar o mapeamento junto aos fornecedores para entender o que o cliente deseja, voltando processos por processos até a chegada ao fornecedor de matéria-prima.

Para a representação dos processos e fluxos são utilizados símbolos, que devem ser padronizados a fim de que todos os colaboradores possam desenhar e entender os mapas e contribuir na aplicação da Produção Enxuta (ROTHER e HARRIS, 2002).

Com o mapeamento atual do fluxo de valor disponível, é possível verificar e eliminar as fontes de desperdícios por meio de um Mapa Futuro, que é constituído com base nos desejos dos clientes ou através do fluxo contínuo ou puxado, produzindo no momento certo aquilo que o consumidor deseja.

O MFV futuro, além de demonstrar as possíveis melhorias, serve para nortear os colaboradores quanto à tomada de decisões para melhorar a situação do sistema produtivo atual. Além disso, o mapa futuro posteriormente acaba se tornando um mapa atual, para que futuras melhorias sejam aplicadas em um processo de melhoria contínua, tornandose um ciclo de melhorias (ROTHER e SHOOK, 2012).

Tendo em posse o mapa do estado futuro, a aplicação de melhorias se torna possível mediante um plano de ação, que deve estar destacado quais medidas devem ser tomadas e os seus respectivos prazos, além de possuir metas quantificáveis e um avaliador das tarefas. A elaboração do plano de ação se baseia nas etapas ilustradas na figura 2.

Figura 2 - Etapas de aplicação do Plano de Ação

\begin{tabular}{|c|c|c|c|}
\hline \multicolumn{4}{|c|}{ Método dos 5W2H } \\
\hline \multirow{4}{*}{5 W } & What & O que? & Que ação será executada? \\
\cline { 2 - 4 } & Who & Quem? & Quem irá executar/participar da ação? \\
\cline { 2 - 4 } & Where & Onde? & Onde será executada a ação? \\
\cline { 2 - 4 } & When & Quando? & Quando a ação será executada? \\
\cline { 2 - 4 } & Why & Por quê? & Por que a ação será executada? \\
\hline \multirow{2}{*}{$2 H$} & How & Como? & Como será executada a ação? \\
\cline { 2 - 4 } & How much & Quanto custa? & Quanto custa para executar a ação? \\
\hline
\end{tabular}

Fonte: Adaptado de Silva et. al, 2013 


\subsection{Ferramentas da Qualidade}

A qualidade é um termo subjetivo que reflete a necessidade das pessoas. Esse termo possui diversos conceitos presentes atualmente na literatura. Para Crosby qualidade é o produto conforme perante suas especificações, já para Deming qualidade é sinônimo de padronização e diminuição da variabilidade, fazendo com que aumente a produtividade e, consequentemente, diminua os custos, expandindo o mercado (SHIBA et al., 1997).

Para garantir a qualidade dos produtos, atingir os objetivos referentes à produtividade e aumentar a competitividade da empresa, é necessário manter a melhoria contínua nos processos de produção. Para isso, existem diversas ferramentas da Qualidade que proporcionam benefícios, tais como o Fluxograma e o Diagrama de Pareto.

Conforme Werkema (1995), o Diagrama de Pareto demonstra de maneira fácil e visual a priorização de diversos temas, problemáticas e conceitos, ou seja, esse gráfico estabelece o arranjo das causas de perdas que devem ser resolvidas, enquanto aquele consiste em uma técnica capaz de descrever claramente o fluxo de um processo por meio de símbolos pré-definidos, que dão suporte aos funcionários para analisarem e redesenharem (se necessário) as etapas de um processo.

\section{MÉTODO DE PESQUISA}

Nesta seção são apresentados os procedimentos metodológicos necessários à realização do estudo de caso. São detalhados o objeto de estudo assim como os procedimentos propostos em sete etapas utilizadas para a realização do estudo de caso.

Utilizou-se uma pesquisa exploratória que, de acordo com Gil (2007), é utilizada para familiarizar-se com o problema em estudo, que pode ser compreendido por meio de um levantamento bibliográfico, entrevistas com líderes e responsáveis das áreas em estudo que tiveram experiências práticas com o problema em questão e por exemplos similares que ocorreram em outras empresas.

O objeto de estudo do trabalho é um processo em uma empresa do setor da saúde, localizada na cidade de Pelotas no RS. Durante as visitas técnicas realizadas na empresa foram analisados alguns processos produtivos para a definição do objeto de estudo.

O método de coleta e análise de dados utilizado neste trabalho foram observação direta e análise de conteúdo. A análise de conteúdo é um conjunto de técnicas de pesquisa 
que visa os sentidos de algum documento, ou seja, após uma investigação essa técnica descreve de maneira objetiva e sistemática um conteúdo presente na literatura (BARDIN, 2009).

$\mathrm{Na}$ observação direta, recorre-se a um método sistemático, no sentido de apreender as realidades observadas, a partir da compreensão, conhecimento dos elementos envolvidos na pesquisa.

A metodologia utilizada no estudo de caso foi estruturada em sete etapas, sendo estas adaptadas a partir dos conceitos desenvolvidos por Rother e Shook (2012), incluindo a coleta e análise de dados de produção e o mapeamento do processo produtivo.

As sete etapas são apresentadas a seguir:

- Etapa 1: Coleta e análise de dados de produção;

- Etapa 2: Seleção de uma família de produtos e definição do componente crítico devido ao elevado percentual de não conformes.

- Etapa 3: Mapeamento de processos por meio de fluxogramas para visualizar facilmente os fluxos de produção;

- Etapa 4: Mapeamento do Fluxo de Valor: Desenho do estado atual;

- Etapa 5: Verificação de oportunidades de melhorias no processo a partir do desenho do estado atual;

- Etapa 6: Proposição de um Plano de Ação para implementação de melhorias;

- Etapa 7: Mapeamento do Fluxo de Valor: Desenho do estado futuro.

\section{ESTUDO DE CASO}

A empresa do estudo de caso está presente no mercado a aproximadamente 40 anos e está inserida no setor da saúde, localizada na cidade de Pelotas, no Rio Grande do Sul. A empresa possui linhas de montagem de equipos médicos, linhas de diálise, bombas de infusão, bombas de seringa, entre outros. A empresa vem crescendo exponencialmente nos últimos anos, o que levou à ampliação da área industrial, ocupando $18 \mathrm{mil} \mathrm{m}^{2}$.

A seleção da família de produtos descartáveis a ser mapeada foi realizada por meio da coleta de dados de volume de produção de todos os produtos da empresa, compreendidos no período entre janeiro e setembro de 2017, os quais foram separados em percentagem de volume de produção. Além disso, foi elaborado outro gráfico em 
pizza das famílias de produtos com maior incidência de volume de produção, sendo separados em quatro famílias: U, V, X e Z. Ambos os gráficos são apresentados na figura 3.

A família $\mathrm{U}$ é composta pelos produtos $\mathrm{E}$ e $\mathrm{J}$; a família $\mathrm{V}$ é formada pelos produtos C, D, G e H; a família X é composta pelos produtos B, F e I; e, por fim, a família Z é formada pelo produto A.

Figura 3- Percentuais de Volume de Produção

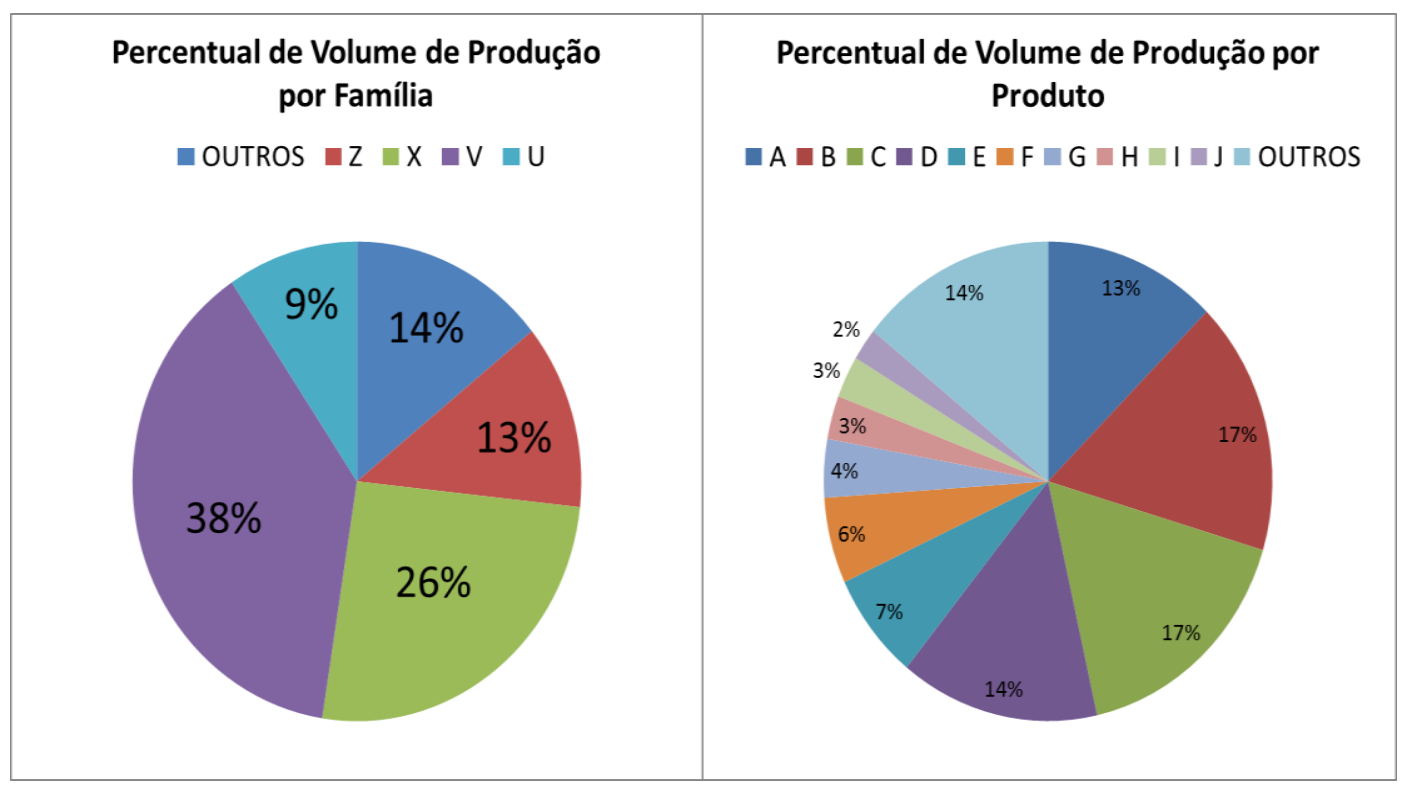

Fonte: Elaborado pelos autores

Analisando os gráficos da figura 3, pode-se verificar que a família que possui maior percentual de produtividade é a família $\mathrm{V}$, composta por 4 produtos $(\mathrm{C}, \mathrm{D}, \mathrm{G}$ e H), compreendendo $38 \%$ de produção em comparação com o total de produtos fabricados no período analisado, sendo ela a família selecionada para a aplicação do MFV.

Na composição desses produtos há um componente considerado crítico, devido ao elevado número de não conformes. O registro de não conformidade se dá nas anotações realizadas no processo de retrabalho, onde é caracterizado o tipo de ação tomada no momento em que o produto foi identificado como não conforme. O item crítico é o tubo PVC, que apresentou $71,75 \%$ dos defeitos encontrados na montagem dos produtos no mês de outubro, conforme figura 4 .

Figura 4 - Percentual de defeitos encontrados durante a montagem 


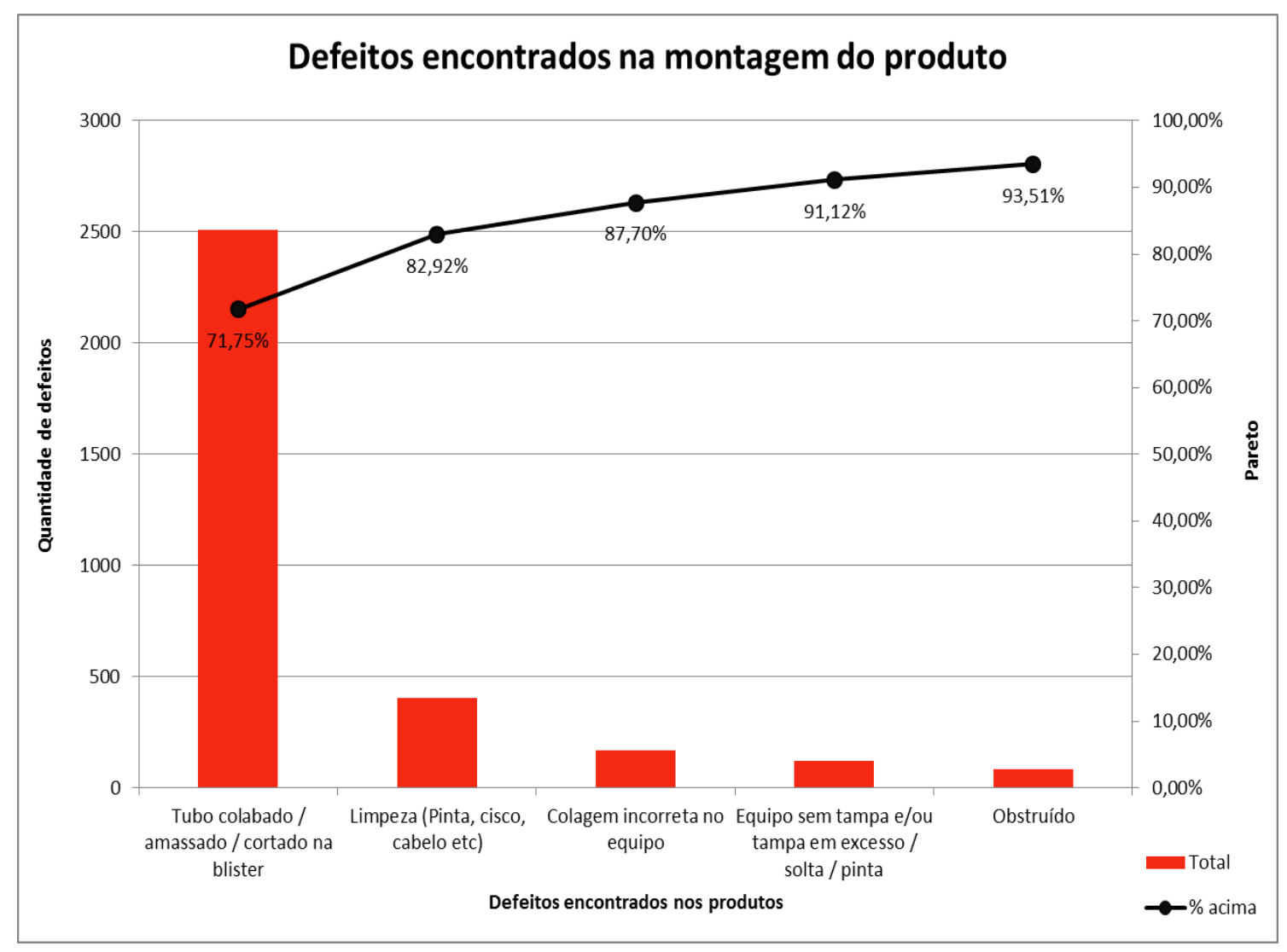

Fonte: Elaborado pelos autores

Para um melhor entendimento do processo de montagem equipos da familia de produtos selecionada, foi realizado um mapeamento de processos por meio de fluxogramas para visualizar facilmente os fluxos de produção. $\mathrm{O}$ fluxograma do processo de montagem equipos da familia de produtos selecionada está ilustrado na figura 5.

Figura 5 - Fluxograma do processo de montagem de equipos 


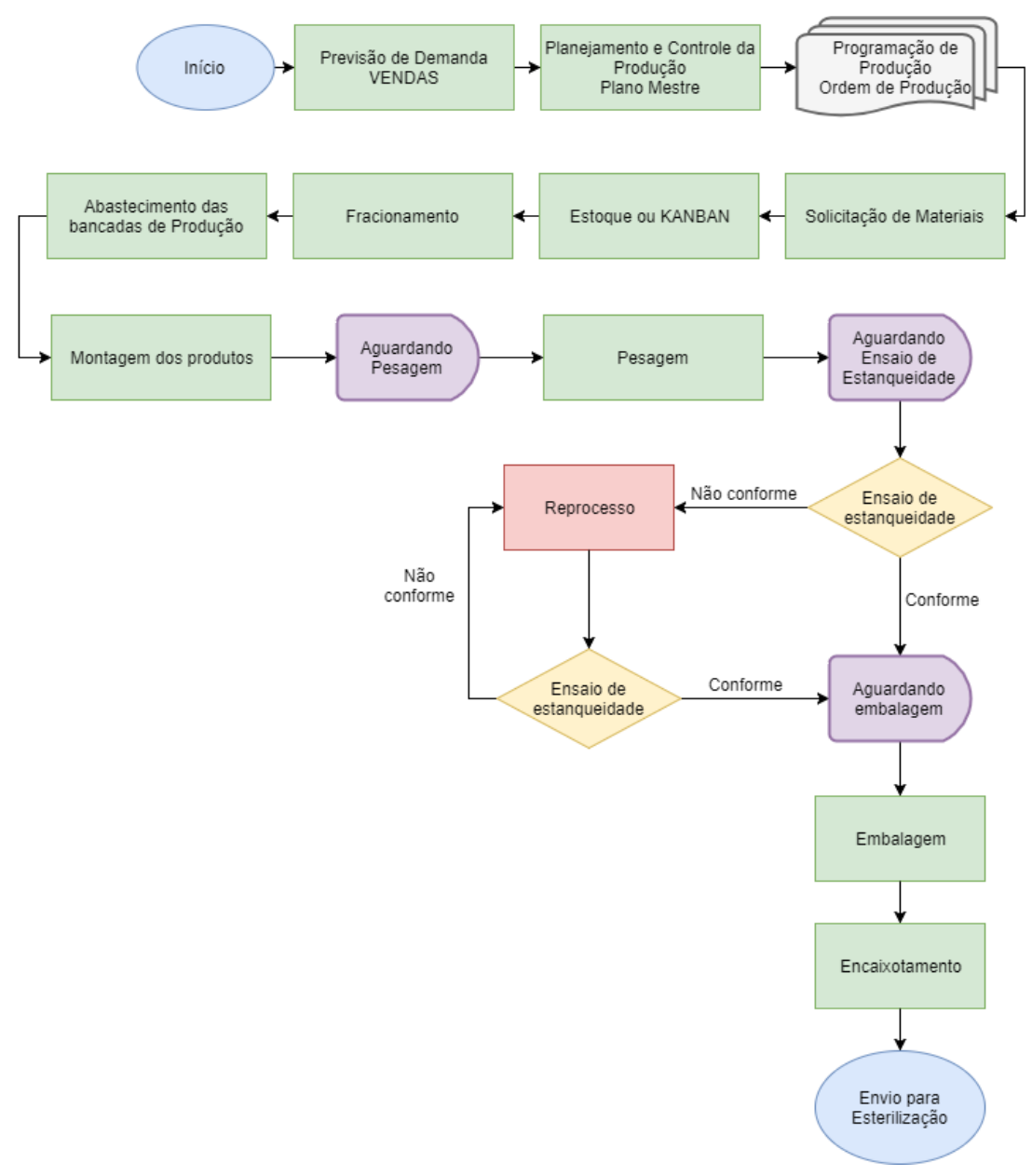

Fonte: Elaborado pelos autores

Após mapear o processo, foi realizado o MFV da família de produtos $\mathrm{V}$, com foco em produtos descartáveis. Esse mapa foi elaborado num processo contrário ao habitual, ou seja, iniciou-se o mapeamento com os clientes e finalizou nos fornecedores, num processo "de trás para frente", acompanhando processo por processo em todo o fluxo.

Durante a coleta dos dados para o mapeamento, foi possível observar alguns tipos de perdas relacionadas à produção e explicadas na revisão bibliográfica, tais como perdas de superprodução, processamento e, principalmente, de produtos não conformes. Esses tipos de perdas não agregam valor ao produto e geram custos indevidos.

A ilustração do mapa do estado atual está presente na figura 6. Além disso, no mapa do estado atual foram elencados e destacados problemas, desperdícios e oportunidades de melhorias (figura 7), que serão incluídas no plano de ação final. 
Figura 6 - Ilustração do mapa do estado atual do MFV

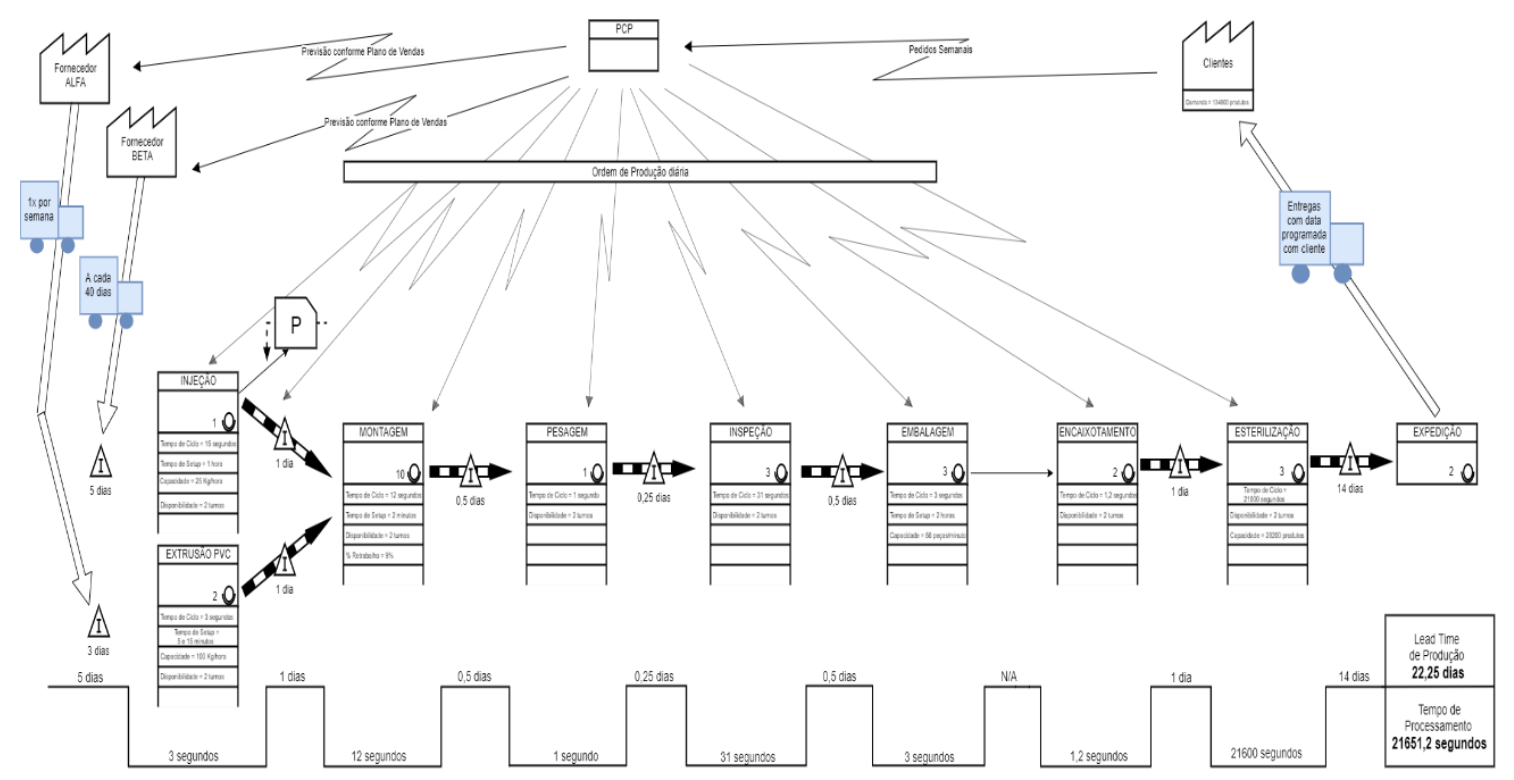

Fonte: Elaborado pelos autores

Figura 7 - Oportunidades de melhorias destacadas no mapa do estado atual do MFV

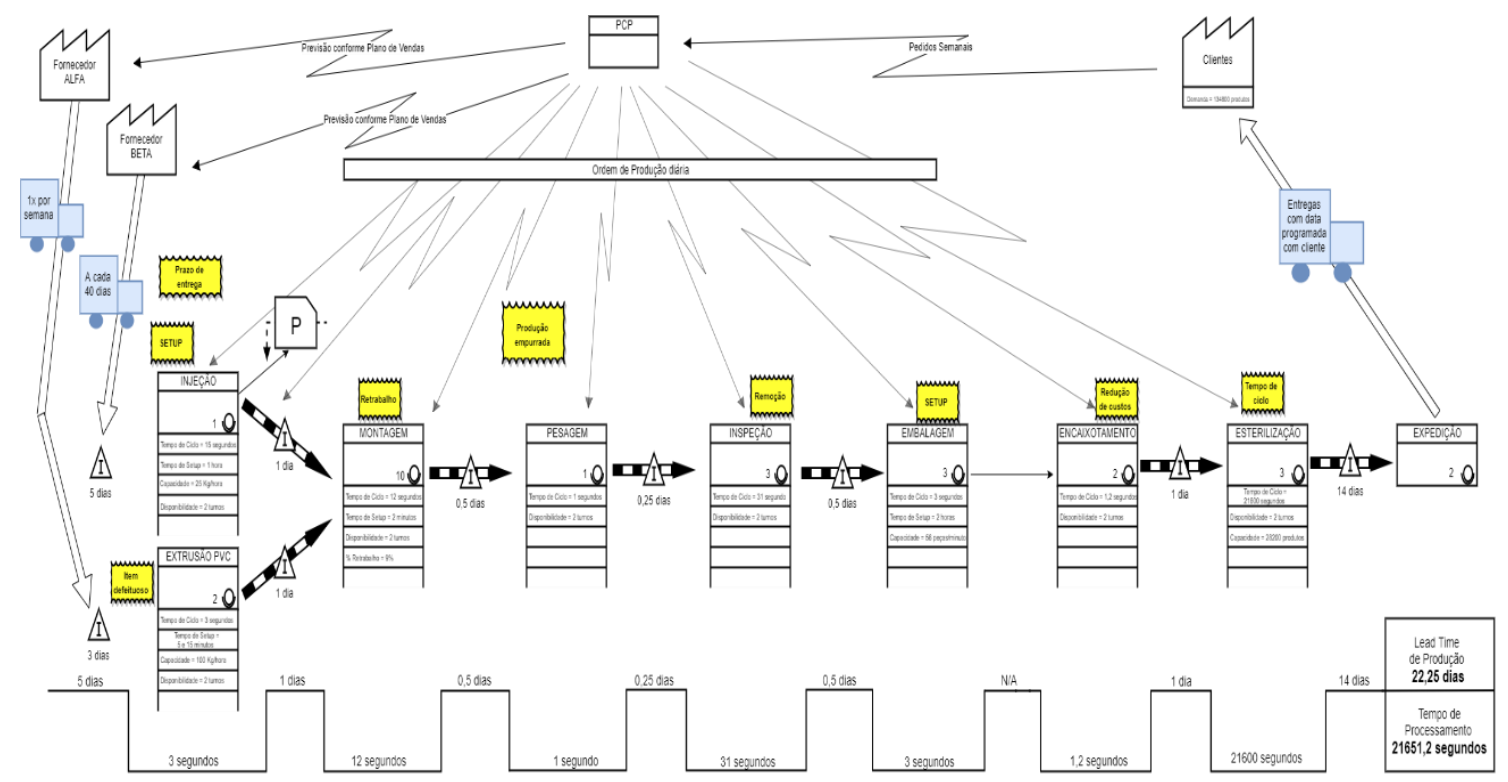

Fonte: Elaborado pelos autores

O fluxo dos processos inicia com a programação e pedidos de compras pelo setor de PCP, aonde chega pedidos para os fornecedores de matéria-prima. A matéria-prima e levada aos setores de injeção e extrusão, onde são fabricados os componentes do produto. Após isso, os produtos finais são montados, pesados, inspecionados, embalados, encaixotados, encaminhados para a esterilização e, posteriormente, levados para o setor de expedição, seguindo um fluxo de produção empurrado.

As oportunidades de melhorias destacadas na figura 7 são: 
a) Elevado tempo de entrega de matéria-prima;

b) Elevados tempos de setup na injeção e no setor de embalagem;

c) Alta taxa de ocorrência de itens defeituosos na extrusão de PVC e retrabalho;

d) Remoção da etapa de pesagem e redução de custos no setor de encaixotamento;

e) Redução do tempo de ciclo do processo de esterilização.

Com o mapa do estado atual, foi possível elaborar um plano de ações para, de maneira organizada, propor implementação de melhorias para então ser elaborado mapeamento do estado futuro. Dessa forma, foram verificadas e analisadas oportunidades de melhorias para resoluções de problemas pertinentes do processo da linha de produção de equipos em estudo. Na tabela 1 são representadas as ações propostas para a criação do mapa do estado futuro.

Tendo em vista os diversos problemas e desperdícios detectados, foram verificadas e analisadas as possíveis melhorias, baseando-se na fácil implementação, no custo envolvido e, principalmente, nos recursos materiais e pessoas que seriam necessários para a implementação do mapa do estado futuro. A representação gráfica do MFV do estado futuro proposto está presente na figura 8.

Uma das principais alterações propostas no processo produtivo foi transformar o fluxo empurrado em puxado, havendo necessidade de construção de armazéns entre alguns processos. Tendo assim, como objetivo controlar todas as movimentações de componentes junto à produção.

Além da inserção de um fluxo puxado, foi proposta a eliminação dos estoques intermediários entre processos, diminuindo a ocorrência de fila de componentes e produtos durante a fabricação dos produtos finais. A utilização da estratégia sequencial FIFO (First In First Out) garante que o primeiro produto a entrar em algum processamento seja também o primeiro a sair, diminuindo perdas provocadas por espera.

Outra proposta de melhoria no mapa futuro foi a utilização do Kanban. Nesse método, só é possível iniciar a produzir um item ou um componente quando é terminado o item em andamento, fazendo com que se produza apenas o necessário no momento correto. 
Tabela 1- Plano de Ação sugerido

\begin{tabular}{|c|c|c|c|c|c|c|}
\hline O quê & Por que & Onde & Quando & Como & $\begin{array}{l}\text { Quanto } \\
\text { custa }\end{array}$ & Quem \\
\hline $\begin{array}{c}\text { Projetar sistema de } \\
\text { armazenagem para tubos } \\
\text { com mais de } 150 \mathrm{~cm} \text { de } \\
\text { comprimento }\end{array}$ & $\begin{array}{c}\text { Elevado número de reclamações } \\
\text { de clientes e matéria-prima } \\
\text { chega a montagem sem } \\
\text { condições }\end{array}$ & $\begin{array}{l}\text { Setor de } \\
\text { Extrusão de } \\
\text { PVC }\end{array}$ & 1 mês & $\begin{array}{c}\text { Desenvolver dispositivo para } \\
\text { melhorar armazenagem dos } \\
\text { tubos após a saída da extrusora }\end{array}$ & $\begin{array}{l}\text { Recursos } \\
\text { orçamen- } \\
\text { tários }\end{array}$ & $\begin{array}{l}\text { Setor de } \\
\text { Engenharia }\end{array}$ \\
\hline $\begin{array}{l}\text { Implementar Troca Rápida } \\
\text { de Ferramentas }\end{array}$ & $\begin{array}{l}\text { Elevado tempo de troca de } \\
\text { moldes }\end{array}$ & $\begin{array}{c}\text { Setor de } \\
\text { injeção de } \\
\text { polímeros }\end{array}$ & 2 meses & $\begin{array}{l}\text { Criar quadros visuais de } \\
\text { ferramentas e treinar } \\
\text { colaboradores }\end{array}$ & $\begin{array}{l}\text { Recursos } \\
\text { orçamen- } \\
\text { tários } \\
\end{array}$ & $\begin{array}{c}\text { Setor de } \\
\text { manutenção }\end{array}$ \\
\hline $\begin{array}{c}\text { Elevado tempo para } \\
\text { entregar a matéria-prima }\end{array}$ & $\begin{array}{l}\text { O tempo de entrega diminui a } \\
\text { flexibilização da produção e } \\
\text { aumente o estoque e lead time }\end{array}$ & $\begin{array}{l}\text { Setor de } \\
\text { estoque }\end{array}$ & 5 dias & $\begin{array}{l}\text { Negociar com fornecedor } \\
\text { prazos que, no mínimo, a } \\
\text { concorrência pode entregar }\end{array}$ & $\varnothing$ & $\begin{array}{l}\text { Setor de } \\
\text { compras }\end{array}$ \\
\hline $\begin{array}{l}\text { Elevado percentual de } \\
\text { retrabalho dos produtos } \\
\text { finais }\end{array}$ & $\begin{array}{c}\text { Componentes chegam à linha } \\
\text { de produção não atendendo as } \\
\text { especificações técnicas, estando } \\
\text { amassadas, por exemplo }\end{array}$ & Montagem & $\begin{array}{c}2 \\
\text { semanas }\end{array}$ & $\begin{array}{c}\text { Treinar colaboradores quanto } \\
\text { às técnicas de armazenagem } \\
\text { de cada item, sendo ele } \\
\text { comprado ou fabricado } \\
\text { internamente } \\
\end{array}$ & $\begin{array}{l}\text { Recursos } \\
\text { orçamen- } \\
\text { tários }\end{array}$ & $\begin{array}{l}\text { Setor de } \\
\text { materiais e } \\
\text { Engenharia }\end{array}$ \\
\hline $\begin{array}{c}\text { Construção de armazéns } \\
\text { "supermercados" de peças } \\
\text { e quadros necessários para } \\
\text { implementar o método } \\
\text { Kanban }\end{array}$ & $\begin{array}{c}\text { Necessidade de passar a } \\
\text { produção de empurrada para } \\
\text { puxada }\end{array}$ & $\begin{array}{c}\text { Em todo o } \\
\text { fluxo do } \\
\text { mapeamento }\end{array}$ & 6 meses & $\begin{array}{c}\text { Treinar colaboradores quanto } \\
\text { às técnicas do método Kanban } \\
\text { Construir os armazéis e orçar } \\
\text { quadros kanbans }\end{array}$ & $\begin{array}{l}\text { Recursos } \\
\text { orçamen- } \\
\text { tários }\end{array}$ & $\begin{array}{c}\text { Setor de PCP e } \\
\text { Engenharia }\end{array}$ \\
\hline $\begin{array}{c}\text { Inserção de sensores } \\
\text { altamente precisos ao final } \\
\text { da montagem dos } \\
\text { produtos } \\
\end{array}$ & $\begin{array}{l}\text { Etapa de pesagem não agraga } \\
\text { valor ao produto }\end{array}$ & Montagem & $\begin{array}{c}2 \\
\text { semanas }\end{array}$ & $\begin{array}{c}\text { Comprar sensores e instalá-los } \\
\text { no setor de montagem }\end{array}$ & $\begin{array}{l}\text { Recursos } \\
\text { orçamen- } \\
\text { tários }\end{array}$ & $\begin{array}{l}\text { Líderes de } \\
\text { Produção e } \\
\text { Engenharia }\end{array}$ \\
\hline $\begin{array}{c}\text { Projetar moldes } \\
\text { intercambiáveis para } \\
\text { melhorar performance }\end{array}$ & $\begin{array}{l}\text { Elevado tempo de troca de } \\
\text { moldes }\end{array}$ & $\begin{array}{l}\text { Setor de } \\
\text { embalagem } \\
\text { de equipos }\end{array}$ & 6 meses & $\begin{array}{c}\text { Desenhar novos moldes por } \\
\text { meio do software SolidWorks } \\
\text { e orçar com empresas externas }\end{array}$ & $\begin{array}{l}\text { Recursos } \\
\text { orçamen- } \\
\text { tários }\end{array}$ & $\begin{array}{l}\text { Setor de } \\
\text { Engenharia }\end{array}$ \\
\hline $\begin{array}{l}\text { Projetar ou buscar } \\
\text { fornecedor de tecnologia } \\
\text { de impressão de dados }\end{array}$ & $\begin{array}{l}\text { Elevado custo na impressão de } \\
\text { etiquetas que são coladas nas } \\
\text { caixas de embarque }\end{array}$ & $\begin{array}{l}\text { Setor de } \\
\text { Encaixota- } \\
\text { mento }\end{array}$ & 3 meses & $\begin{array}{c}\text { Buscar e avaliar fornecedores } \\
\text { da tecnologia ou projetar a } \\
\text { impressora para implementar } \\
\text { no setor }\end{array}$ & $\begin{array}{l}\text { Recursos } \\
\text { orçamen- } \\
\text { tários }\end{array}$ & $\begin{array}{l}\text { Setor de } \\
\text { Engenharia }\end{array}$ \\
\hline $\begin{array}{l}\text { Alteração do tipo de } \\
\text { esterilização utilizada }\end{array}$ & $\begin{array}{l}\text { Elevado tempo de ciclo para } \\
\text { esterilizar os produtos }\end{array}$ & $\begin{array}{c}\text { Setor de } \\
\text { Esterilização }\end{array}$ & 1 ano & $\begin{array}{c}\text { Buscar e avaliar fornecedores } \\
\text { da tecnologia } \\
\text { Testar novas alternativas de } \\
\text { esterilização } \\
\text { Validar junto à ANVISA } \\
\text { Adaptar o setor de } \\
\text { esterilização } \\
\end{array}$ & $\begin{array}{l}\text { Recursos } \\
\text { orçamen- } \\
\text { tários }\end{array}$ & \begin{tabular}{|c|} 
Setor de \\
Engenharia \\
Qualidade \\
Coordenação \\
Industrial \\
Diretoria \\
Confiabilidade \\
\end{tabular} \\
\hline
\end{tabular}

Fonte: Elaborado pelos autores 
Figura 8 - Ilustração do MFV futuro

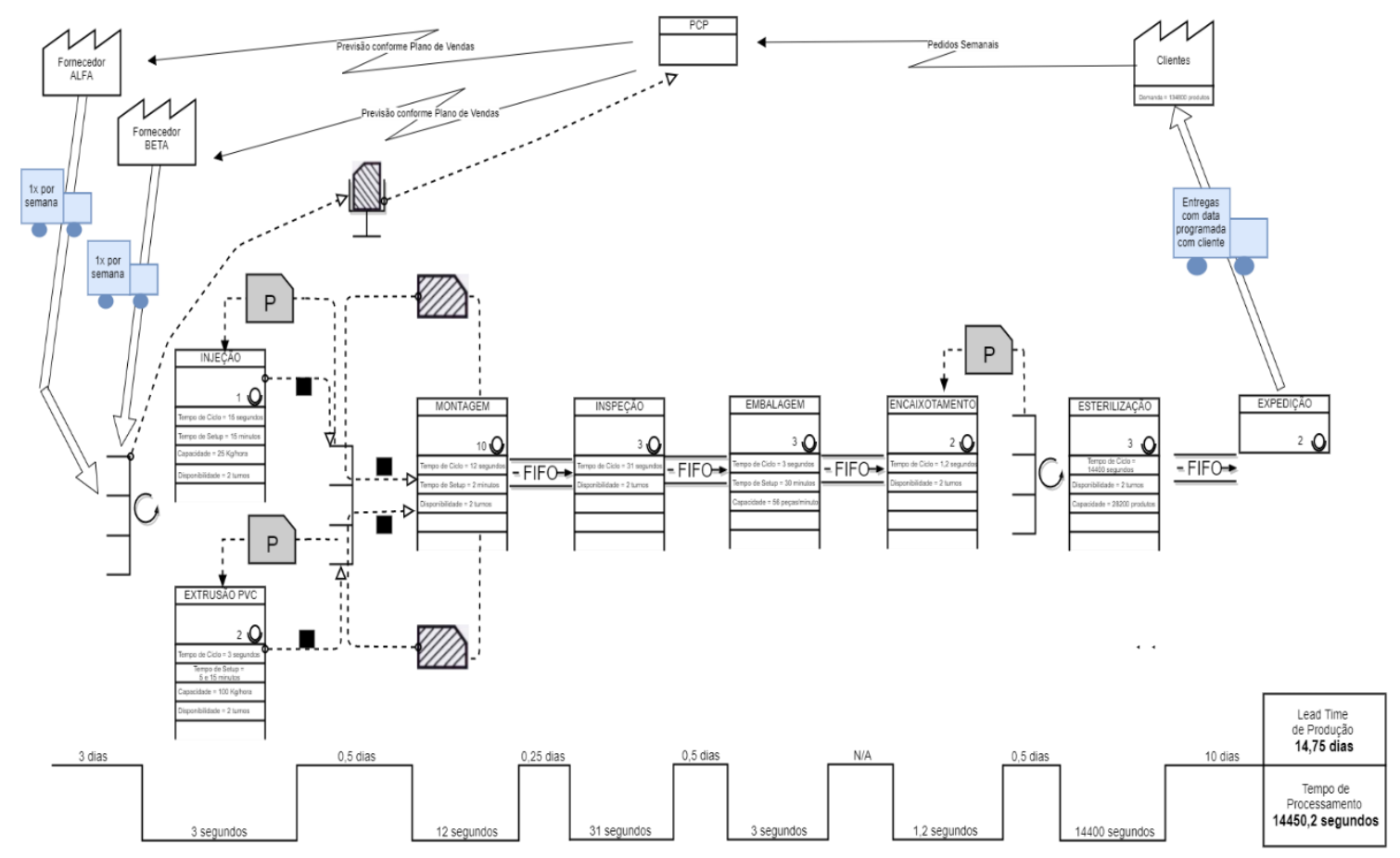

Fonte: Elaborado pelos autores

Após a análise do estado atual e a proposição de melhorias do estado futuro, foi construído um quadro com os tempos medidos, identificando as principais mudanças e os principais ganhos, ilustrados na tabela 2 .

Tabela 2 - Possíveis resultados com a aplicação do MFV

\begin{tabular}{c|c|c|c|c}
\hline Melhorias & Atual & Futuro & Ganho real & Percentual \\
\hline $\begin{array}{c}\text { Entrega da } \\
\text { Matéria-Prima }\end{array}$ & 40 dias & 7 dias & 33 dias & $\mathbf{8 3 \%}$ \\
\hline $\begin{array}{c}\text { Tempo de setup } \\
\text { Injeção }\end{array}$ & 30 minutos & 15 minutos & 15 minutos & $\mathbf{5 0 \%}$ \\
\hline $\begin{array}{c}\text { Tempo de setup } \\
\text { Embalagem }\end{array}$ & 2 horas & 30 minutos & 1,5 horas & $\mathbf{7 5 \%}$ \\
\hline $\begin{array}{c}\text { Tempo de ciclo } \\
\text { Esterilização }\end{array}$ & 21600 segundos & 14400 segundos & 7200 segundos & $\mathbf{3 3 \%}$ \\
\hline $\begin{array}{c}\text { Lead Time de } \\
\text { Produção }\end{array}$ & 22,25 dias & 14,75 dias & 7,5 dias & $\mathbf{3 4 \%}$ \\
\hline
\end{tabular}




\begin{tabular}{c|c|c|c|c}
$\begin{array}{c}\text { Tempo de ciclo } \\
\text { Total }\end{array}$ & 21651,2 segundos & 14450,2 segundos & 7201 segundos & $33 \%$ \\
\hline
\end{tabular}

Fonte: Elaborado pelos autores

\section{DISCUSSÃO DOSRESULTADOS OBTIDOS}

A aplicação das sete etapas metodológicas propostas possibilitou a realização sistemática do estudo de caso. A coleta dos dados de volume de produção foi importante para a seleção de uma família de produtos. A análise dos defeitos encontrado nos produtos, ilustrada na figura 4 assim como o mapeamento do processo de montagem de equipos, ilustrado na figura 5 , foram etapas preliminares importantes para o entendimento do processo. Estas etapas contribuíram e facilitaram a construção do MFV do estado atual.

Assim como Rother e Shook (2012) descrevem em sua metodologia de aplicação do MFV, foi possível visualizar o os fluxos de materiais e informações como um todo, possibilitando enxergar problemas e gargalos. Dessa maneira, no intuito de resolver os problemas e melhorar os processos produtivos foi possível elencar nove ações, as quais foram estruturadas de maneira organizada e objetiva através de um plano de ação.

Os resultados apresentados na tabela 2 permitiram estimar quantitativamente os principais ganhos percentuais que seriam obtidos com a implementação das melhorias propostas no plano de ação elaborado.

Segundo Rebelato et al. (2008) a falta de continuidade e dinamismo interativo na aplicação dos métodos da qualidade pelas empresas é uma realidade. Uma explicação para isso reside no fato de que cada método ou ferramenta foi criado ao seu tempo, por uma organização específica que tinha um problema gerencial pontual e o objetivo de sanálo. Dessa forma, a aplicação prática em ambiente industrial dos métodos da qualidade ainda é limitada nas indústrias brasileiras, o dificulta a compreensão dos problemas e por consequência ação gerencial para solucioná-los de forma otimizada.

Neste estudo buscou-se aplicar de forma sistemática e integrada métodos da de mapeamento de processo, mapeamento de fluxo de valor, conceitos de produção enxuta e algumas ferramentas da qualidade para identificação e resolução de problema real em uma indústria de produtos médico-hospitalares. O Gap abordado e solucionado neste trabalho foi conciliar a aplicação sistemática e formalizada de métodos teóricos da qualidade para solução e otimização de um problema real de produção.

Desta forma, o método de pesquisa aplicado no estudo de caso contribui para sociedade, uma vez que a teoria e a prática são aplicadas no ambiente industrial 
fomentando a cultura da otimização dos processos produtivos e promovendo a divulgação de seus resultados.

\section{CONSIDERAÇÕES FINAIS}

A realização deste trabalho permitiu um melhor entendimento teórico-prático das ferramentas da produção enxuta, da qualidade, ao mapeamento de processos e sobretudo ao MFV, através do estudo dos seus conceitos assim como de suas aplicações no estudo de caso.

Um desafio encontrado na elaboração desse trabalho foi o setor onde a indústria em estudo está inserida no mercado. Normalmente, são encontrados na literatura artigos e trabalhos aplicados com foco no setor industrial automobilístico, uma vez que grande parte das ferramentas, vistas na revisão bibliográfica, foram elaboradas para atender demandas desse setor.

A realização do MFV foi facilitada devido à aplicação inicial do mapeamento de processos, o qual foi construído por meio da utilização de um fluxograma, sendo essencial para o entendimento de todas as etapas do processo produtivo.

A mudança do sistema de produção empurrado para um sistema puxado, sobretudo a proposição da implantação do método FIFO entre os processos se deu a partir da comparação entre o MFV atual e o MFV futuro, o que demonstra a dimensão e os impactos das melhorias sugeridas.

Por fim, pode-se concluir que os objetivos traçados no início desse trabalho foram atingidos, tendo em vista que o MFV forneceu e ilustrou os principais desperdícios e problemas de uma linha de produção. Assim, o MFV foi importante para a proposição de um sistema futuro que poderá, por meio dos planos de ações desenvolvidos, melhorar todo o fluxo de materiais e informações do processo produtivo, podendo reduzir e até mesmo eliminar estoques intermediários e melhorar o lead time de produção. O mapa futuro também servirá como auxílio para futuras análises de melhorias, tornando esse ciclo contínuo.

É importante ressaltar que a ferramenta de MFV se mostrou bastante importante, mas sua simples utilização sem o domínio dos conceitos da produção enxuta faz com que sua utilidade seja bastante restrita. Ela serve apenas para evidenciar os problemas e, muitas vezes nem isso, pois quem a utiliza precisa estar atento aos desperdícios. Além do 
mais, a ferramenta não sugere soluções, as soluções dependem do conhecimento e experiência em lean de quem a utiliza.

Quanto às possibilidades de trabalhos futuros, especificamente para a empresa estudada, criar uma logística lean para aumentar a capacidade produtiva e reduzir o lead time poderia ser um próximo trabalho.

\section{REFERÊNCIAS}

ANTUNES, J. Sistemas de Produção: conceitos e práticas para projeto e gestão da procução enxuta. Ed. Bookman: Porto Alegre, 2008.

BARDIN, L. Análise de conteúdo. Lisboa: Edição 70, 2009.

CHEUNG, Y.; BAL, J. Process analysis techniques and tools for business improvements. Business Process Management Journal, v. 4, n. 4, p. 274-290, 1998.

CORREAA, H.L.; GIANESI, I.G.N.; CAON, M. Planejamento, Programação e Controle da Produção. São Paulo: Atlas, 1996.

GAITHER, N.; FRAIZER, G. Administração da Produção e Operações. 8. ed., São Paulo: Pioneira Thomson Learning, 2001.

GIL, A.C. Como Elaborar Projetos de Pesquisa. 4. ed. São Paulo: Atlas 2007.

MARTINS, P. G.; LAUGENI, F.P. Administração da Produção. 2. ed. Saraiva, São Paulo, 2005.

OHNO, T. O Sistema Toyota de Produção - Além da produção em larga escala. Ed. Bookman: Porto Alegre, 1997.

PINTO, L.E.R. Combinação entre as Técnicas de Fluxograma e Mapa de Processo no Mapeamento de um Processo Produtivo. In IEPG, 2007 Disponível em: <http://www.leansixsigma.com.br/acervo/>

ROTHER, M.; HARRIS, R. Criando fluxo continuo - um guia de ação para gerentes engenheiros e associados da produção. Lean Institute Brasil, São Paulo, 2002.

ROTHER, M.; SHOOK, J. Aprendendo a enxergar: mapeando o fluxo de valor para agregar valor e eliminar o desperdício. Lean Institute Brasil, São Paulo, 2012.

SHIBA, S.; GRAHAM, A.; WALDEN, D. TQM - Quatro revoluções na gestão da qualidade. Porto Alegre: Artes Médicas, 1997.

SHINGO, S. O Sistema Toyota de Produção do Ponto de Vista da Engenharia de Produção. Porto Alegre: Bookman. 1996.

SILVA, O. D; RORATTO, L.; SERVAT, M. E.; DORNELES, L.; POLACINSKI, É. Gestão da Qualidade: Aplicação da Ferramenta 5W2H como plano de ação para 
Projeto de abertura de uma empresa. Disponível em: <http://www.fahor.com.br/publicacoes/sief/2013/gestao_de_qualidade.pdf>. Acesso em: 29 Jun. 2017.

SILVEIRA, C. B. Mapeamento do fluxo de valor. Disponível em: $<$ https://www.citisystems.com.br/mapeamento-fluxo-valor-1/>. Acesso em 07 Jun. 2017.

SLACK, N.; CHAMBERS, S.; JOHNSTON, R. Administração da Produção. São Paulo: Editora Atlas, 1997.

TSENG, M. M.; QINHAI, M.; SU, C. J. Mapping Customers' Service Experience for Operations Improvement. Business Process Management Journal, v. 5, n. 1, p.50-64, 1999.

WERKEMA. M. C. C. Ferramentas estatísticas básicas para o gerenciamento de processos. Belo Horizonte: Fundação Cristiano Ottoni, 1995.

\section{Recebido em: 01/06/2021}

Aprovado em: 25/06/2021

Publicado em: 30/06/2021

\section{Autores:}

\section{Ariane Ferreira Porto Rosa}

Doutora em Automatique et Informatique Appliquées (Spécialité Génie Industriel Qualité), pela Université de Nantes.

Instituição: Universidade Federal de Pelotas, Centro de Engenharias, Curso de Engenharia de Produção.

Endereço: Rua Benjamin Constant, 989, Bairro Porto, Pelotas-RS, Brasil.

E-mail: afprosa61@gmail.com

\section{Eduardo Angelin}

Bacharel em Engenharia de Produção UFPel

Instituição: Centro de Engenharias, Universidade Federal de Pelotas

Endereço: Centro de Engenharias, Prédio da Antiga Cotada, Rua Benjamin Constant, 989 - Porto, Pelotas - RS, Brasil - 96010-020

E-mail: eduardoangelin.pl@gmail.com

\section{Rogério Royer}

Doutor em Administração de Empresas pela Universidade Federal do Rio Grande do Sul.

Instituição: Universidade Federal de Pelotas, Centro de Engenharias, Curso de Engenharia de Produção.

Endereço: Rua Benjamin Constant, 989, Bairro Porto, Pelotas-RS, Brasil.

E-mail: rogroyer@gmail.com 